\title{
ResearchArticle
}

\section{A new record on sheath blight disease of finger millet from Uttarakhand, India}

\author{
Bijender Kumar
}

\section{SUMMARY}

Sheath blight, a new disease of finger millet appeared in Kotabagh, Nainital, situated in hills of Uttarakhand. Wide spread occurrence of this disease in this region can have alarming consequences as it causes serious yield loss. This could adversely affect the livelihood of marginal farmers of Uttarakhand. The causal agent was identified as Rhizoctonia solani Kuhn. The pathogenicity of the fungus was established by artificial inoculation on healthy plants.

Key Words : Finger millet, Small millet, Sheath blight, Rhizoctonia solani, Eleusine coracana

How to cite this article : Kumar, Bijender (2019). A new record on sheath blight disease of finger millet from Uttarakhand, India. Internat. J. Plant Sci., 14 (2): 77-80, DOI: 10.15740/HAS/IJPS/14.2/77-80, Copyright@ 2019: Hind Agri-Horticultural Society.

Article chronicle : Received : 25.03.2019; Revised : 07.06.2019; Accepted : 19.06.2019

\section{AUTHOR FOR CORRESPONDENCE}

Bijender Kumar, Department of Plant Pathology, College of Agriculture, G.B. Pant University of Agriculture and Technology, Pantnagar, U.S. Nagar (Uttarakhand) India

Email : bij1005@yahoo.co.in 